\title{
NEIGHBORHOOD SCHOOLS AND INTEGRATION
}

\author{
Robert M. Fearn \\ North Carolina State University (Raleigh)
}

EDITOR'S NOTE. A recent pair of Supreme Court decisions, the first, upholding the busing of children in Charlotte, North Carolina, and the second, upholding the right of citizens of the State of California to impose statuatory limitations by public referendum upon the extension of busing between communities, suggest the vital importance of open-housing in fact as well as in theory. The following paper by Professor Robert M. Fearn of North Carolina State University at Raleigh addresses these issues. The paper suggests the possibility of simultaneous solutions to the busing and neighborhood integ ration problems.

This paper, written before the Supreme Court decision was rendered in the Charlotte-Mecklenburg case, presents some provocative ideas which merit further analysis. In this vein, the editors have chosen to deviate from the "usually accepted" article format in this case so that attention may be focused upon the economics of the issues raised here.

It goes without saying that in this, as in all other pieces appearing in the journal, the editors take no objective position either in support or in opposition to the ideas expressed by the authors.

SEB

During 1970, the Raleigh, North Carolina school system was charged by the NAACP Legal Defense Fund and the U.S. Department of Health, Education and Welfare with failing to disband its allegedly segregated public school system. The Raleigh case, now in Federal District Court (April 1971) is similar although not identical to the Charlotte, North Carolina case,which was under consideration by the U.S. Supreme Court during late 1970 and early 1971. Because it was reasonable to expect that the Supreme Court would provide some guidance with its ruling on the Charlotte case, the Raleigh case was held in abeyance; thus providing an opportunity for a lively public "multilogue." This article emerged from that "multilogue."

On November 29, 1970, the Raleigh News and Observer published a "Point of View" editorial entitled "Neighborhood Schools and Integration." Although the editorial is addressed only to school and housing problems in Raleigh, it is based upon a broader model--namely the theory of cartels. As a consequence, its policy recommendations extend far beyond the geographic confines of Raleigh, N.C. The complete unedited text of the "Point of View" editorial is reproduced below; supplemented and extended by an analytical commentary.

Open Letter to Judge Algernon Butler and the Raleigh School Board

October 10,1970

\section{Ladies and Gentlemen:}

Several years ago, a few far-sighted public officials and private citizens proposed a program of scattered public housing in North and West Raleigh as a partial solution to our housing problems and as a vehicle for school desegregation. Had the citizens of Raleigh been more receptive to the propos- 
al at that time, we might now be better prepared to maintain a system of neighborhood schools instead of being faced with high-cost, crosscity busing, "pairing, "."satellite areas, " and considerable instability in school as signments from year to year. Much of the anguish which may result from the coming legal decisions concerning the schools can, I believe, still be avoided if the Courts and/or the Raleigh School Board will explicitly recognize the positive contribution of the long awaited, but now emerging scattered sites public housing program.

Throughout this letter, I assume that the Courts will require some form of busing to achieve equal educational opportunities for all children within the city school district, and that some plan, like the Finger or the Holloman plan, will be instituted. As I understand them, both the Finger plan, proposed by the NAACP, and the Holloman plan, proposed by citizens in East and South Raleigh, imply substantial busing so as to afford all students with equal educational opportunities as defined by the Courts and by our common ethical standards. The Holloman plan helps to minimize transportation costs, but it--like the Finger plan--faces the very real possibility that the assignment plan itself will induce changes in housing patterns resulting in resegregation. Moreover, both the Finger plan and the Holloman plan take existing housing patterns as given. Neither recognizes present plans for the construction of a large public housing project on Kent Road and of four other smaller projects in the north and northwestern parts of the school districts. Such an omission can have very serious results. We all know that the busing problem is tied to the housing problem, and it is folly to treat them as separate or separate issues. The success of the rural areas (where black and white housing is more interspersed), in converting to desegregated school systems is eloquent testimony to this effect.

Let me illustrate the complications which will arise in any assignment plan which does not take changes in neighborhood racial composition explicitly into account by discussing briefly the public housing site nearest to my home. It is very likely that the Kent Road project will be built in the near future; hopefully in a modified form more consistent with the now well-recognized small sites approach. With such a modified project, I am confident that the hard work done by the West Raleigh Civic Association will "pay off," and that there will be no repeat of the white exodus produced by the very large Apollo Heights development. Indeed, the citizens of West Raleigh have already declared"their firm intention to welcome and assimilate the new residents into the active life of the neighborhood." Hopefully, success in neighborhood acceptance of other projects in North and Northwest Raleigh.

A modified Kent Road project will raise the racial proportions in the A. B. Combs school district to a level of approximately equal to the black-white population ratio of the city. The other scattered sites presumably will produce a similar condition in four additional elementary school districts in the north and northwest. When these projects are completed and occupied, move ment of the integrated student body from these school districts to other, more segregated ones will make only a weak contribution to racial balance in the latter districts. This is true for any level of schooling; elementary, junior high, or high school. This kind of thinking appears to have been the reason why the Finger plan proposed relatively few changes at Enlow and Aycock Schools and at the Mount Vernon-Goodwin Elementary School in West Raleigh. In this light, it is ironic that the Finger plan proposes that the present black and white children from the A.B. Combs district be assigned to Washington School for the fifth and sixth grades, Carnage Junior High for the seventh through the ninth grades, and Ligon High School for the tenth through the twelfth grades. Thus, if the Finger plan is adopted, the A. B. Combs district-soon to become a racially balanced one--will have "neighborhood schools" outside their neighborhood from the fifth through the twelfth grades to which 
the children must be bused. Completion of the Kent Road project will reduce A. B. Combs' contribution to racial balance in the South Raleigh schools, and the school assignment plan will then have to be substantially modified to reflect this change. A similar scenario can be developed for the other four districts scheduled for public housing.

High public and private transportation costs, changing neighborhood patterns, the very real benefits of neighborhood schools, the need for neighborhood stability, and the avoidance of public trauma each fall argue that any racial assignment plan should contain a guideline which will lead us back to neighborhood schools on a racially integrated basis. Without such a guideline, racial assignment plans run the very great risk of being destabilizing in the short run and destructive of both integ ration and neighborhood schools in the long run. Because racial assignment plans will necessarily have different effects upon different neighborhoods and because these differences will create pressures and opportunities for relocation of families, the assignment plans will tend to be self defeating to the degree that whites "move out" of certain districts and resegregation occurs.

Several citizens of West Raleigh have developed a guideline designed to minimize the pressures for resegregation, to ease the difficulties of adjustment to a fully desegregated school system, and to take explicit account of the positive contributions of the scattered site, public housing program. That guideline is as follows:

WHEREVER THE ELEMENTARY SCHOOL DISTRICT HAS
ALREADY BECOME SUBSTANTIALLY INTEGRATED BY PU-
BLIC OR PRIVATE ACTION--SO THAT IT POSSESSES RACI-
AL PROPORTIONS CLOSE TO THOSE FOR THE CITY AS A
WHOLE--OR WHEREVER FIRM PLANS OR CLEARLY SPE-
CIFIED PROJECTS WILL PRODUCE SUCH A SITUATION IN
THE NEAR FUTURE, THE NEIGHBORHOODSCHOOL SYSTEM
SHOULD NOT BE ALTERED AND ALL CHILDREN IN SUCH
DISTRICTS SHOULD BE ASSIGNED TO THE NEAREST ELE-
MENTARY, JUNIOR HIGH, AND HIGH SCHOOS TO THE EX-
TENT OF THE PHYSICAL CAPACITIESOF THE RESPECTIVE
SCHOOLS.

This guideline would serve the legitimate objectives of the NAACP and would have many additional benefits. The positive steps taken by various neighborhoods and by the Raleigh Housing Authority would be explicitly recognized. Transportation costs would be reduced as compared to those imposed by plans employing "pairing," "satellite areas," and other devices. Moreover, assignment plans consistent with this guideline would tend to stabilize those neighborhoods which have already experienced or are undertaking the personal and social adjustments associated with housing desegregation. In this way, the guideline would help to reduce or eliminate the need for continued sequencial alternations in student assignment plans. Perhaps most important, plans based upon such a guideline would provide a compelling incentive for the neighborhoods in North and Northwest Raleigh to accept public housing and/or integrated occupancy. For example, parents of children in the Aldert Root School; already operating at substantially less than capacity, would have a strong incentive to find land for a public housing site in the district and/or to support and encourage open occupancy in order to maintain their neighborhood school as a viable unit and to gain assurance that their older children would attend nearby junior high and high schools. Reasonable people in most districts should prefer public housing and/or integrated occupancy on a private basis to an unstable and unstabilizing busing system. Of course, many families in the Root district have already chosen 
another path--that of the segregated or largely segregated private academy. Stabilization of schooling patterns might even help them to find their way back to the public school system--a system which needs their wholehearted support.

I submit that as long as the costs and problems of racial adjustments are distributed in an unequal fashion among the various white neighborhoods in West and North Raleigh, housing patterns will change in a perverse fashion, the schools will be in a chaotic condition, and the jockeying for special privilege based upon social position will continue. Plans based upon the guideline suggested here will tend to equalize adjustment costs, provide for a return to neighborhood schools under integrated conditions, and help promote a rapid and peaceful transition to school integration throughout the city with a minimum and a gradually reducing amount of busing.

In general, plans based upon such a guideline would be of immense assistance in promoting equal housing and equal educational opportunities while retaining the benefits of neighborhood schools. Certainly, we should design our public policies to reduce and then eliminate the separation of blacks and whites into separate and hostile geographic areas. If we do not do so, we experience intentional and unintentional "block-busting" by public and private agencies in neighborhood after neighborhood, coupled with massive busing and growing racial tension. In short, we must design our public policies to make certain that Raleigh, North Carolina, does not become another Newark, New Jersey, in housing patterns and raical attitudes. It is with this focus that I respectfully submit this policy guideline for your thoughtful consideration.

\section{Analytical Commentary}

The article reprinted above is an exercise in the economics of the second best. In the absence of zoning restrictions, building codes, externalities, trade unions, public housing authorities, and a number of activities by real estate and financial agencies allegedly related to racial and/or religious dis crimination in housing and with given tastes, income distribution patterns and adquate information on the quality of housing, the market would act.to distribute housing services among prospective buyers in a socially optimal way. In a paraphrase of Adam Smith's well known quote, we might say that:

The whole of the advantages and disadvantages of different units of housing services must in the same metropolitan area be either perfectly equal or continually tending to equality. If in the same metropolitan area, there were any units of housing services evidently more or less advantageous than the rest, so many people would seek to acquire them or crowd into the specific housing area in the one case or dispose of them and flee the area in the other, that their net advantages would soon return to the level of other housing services. This at least would be the case in a society where things were left to follow their natural course.

Following the theory of the second best, ${ }^{2}$ the existence of a number of easily recognized interferences in the housing market raises the possibility that additional restrictions might move the housing market back in the direction of Pareto optimality rather than away from it as in the case of a single imperfection. We are left, therefore, in discussing housing policy with the need to examine the specific effects of each new policy proposal; given the presumption that the existing allocation of housing services among buyers and prospective buyers may already be nonoptimal. 
Because such an examination is an extremely difficult undertaking given the lack of information with which to determine the separate and combined effects of the various imperfections, it would appear that economists might have little to say about the even more complex problem of housing patterns and school "busing." Nevertheless, there are insights into the busing and school problems which can be obtained by the creative application of economic theory. The "Point of View" editorial represents such an application.

The essence of the editorial is the recognition of a cartel problem within each metropolitan area. Given the stance of the courts concerning school integration regardless of housing patterns and given the obvious benefits of neighborhood schools (benefits unrelated to the racial composition of the population), it would "pay" the entire community to integrate its neighborhoods, thus complying with the law, avoiding costly busing, and maintaining neighborhood schools. More pointedly, it would pay all white citizens in these communities, regardless of their individual tastes concerning racial integration, to endorse policies encouraging scattered public housing--largely occupied by blacks--and open occupancy. To the degree that these public activities can forestall or reduce wholesale "busing," lower educational costs (or higher benefits per educational dollar can be achieved. However, as in all cartel problems it simultaneously pays each cartel member (neighborhood or family) to postpone (or perhaps avoid entirely) his own acquiescence to or acceptance of public housing or open occupancy for such changes will necessarily impose pecuniary and/or nonpecuniary costs upon him and his neighbor hood. To the degree that some existing white neighborhoods can be induced or forced by public or private actions to become integrated and to the degree that such integration is sufficient to relieve legal pressures, temporarily or permanently, noncomplying or recalcitrant neighborhoods and their "citizens" will have a "free ride." Moreover, to the degree that whites regard neighborhood integration as a net disadvantage, neighborhoods which become integrated run the very great risk of observing an exodus to neighborhoods with greater resistance to racial accommodation in housing. The net effects of this dynamic process are (1) movement of an ethnic neighborhood or ghetto to a new location on the one had and (2) increases in property values on the non complying white neighborhoods on the other. The pattern is by now too fam iliar to require extensive elaboration.

What is needed to achieve the social objectives of stable school and/or housing integration is a strong incentive designed, first, to induce neighborhoods to comply, and, second, to assure that most white families will remain in newly integrated areas. The threat of cross-community busing combined with the emergence of scattered public housing programs creates the oppo $\mathrm{r}$ tunity for such an incentive; one which will counterbalance the historic inducements for a white exodus from newly integrated areas. The policy guideline proposed above provides just such an incentive, which alternatively may be viewed as an internal policing device for the cartel. ${ }^{3}$ It serves simultaneously to induce and force all neighborhoods within the political jurisdiction to move in the direction of compliance and to assure "neighborhood schools" for those individuals who comply. "Busing" would be restricted to children from noncomplying neighborhoods.

Alternatively stated, downward shifts in the relative demand by whites for housing services in complying neighborhoods would be counterbalanced by upward shifts in the demand for housing in neighborhoods which are immune from "busing" and from the insecurities produced by that eventuality. The countervailing (or more than countervailing) shift is produced by making the probability fo busing from integrated or soon-to-be integrated neighborhoods - 0.0 while raising the probability of "busing" in noncomplying areas to approximately 1.0. One might also describe the function of the guideline as an attempt to "buy out" the tastes of whites concerning interracial living 
while requiring noncomplying areas to payhigh costs for their tastes. Traditional black neighborhoods, of course, will experience some "busing" in the short run in either case. The end result, however, can be expected to be different. In the process directed by the guideline, not only might one expect the emergence of more integrated housing and school patterns, but one might also expect the time necessary to achieve stably integrated schools and housing systems to be of short duration; given the strong incentives for all neighborhoods to comply. 4

Finally, note that the guideline also provides the basis for a political coalition between whites already living in integrated or "fringe" areas, blacks who seek the better living and school conditions which are to be found largely outside ghetto areas, and traditional black and white liberals who seek to reduce the racial separateness of our society. Often, the white neighbor hoods expected to adjust to interracial living are only those which are populated by lower and lower-middle income white families and which are adja cent to traditional black neighborhoods. The scattered public housing program coupled with a guideline of the type proposed here relieves the disproportionate pressures on the fringe neighborhoods while improving the prospects for overall integration of schools and neighborhoods.

Thus, if one assumes racial integration of the schools or of the schools and the society to be a desirable policy objective, the program suggested here--given a political jurisdiction of an appropriate size ${ }^{5}$-could make a substantial contribution to that objective albeit that a Pareto optimal solu tion would in all likelihood still elude us. 
FOOTNOTES

${ }^{1}$ See Adam Smith, An Inquiry into the Nature and Causes of Wealth of Nations, Vol. I (London: G. Bell and Sons, Ltd., 1921-Reprinte $\overline{d)}, \overline{\text { p. } 101 .}$

${ }^{2}$ R. G. Lipsey and Kelvin Lancaster, "The General Theory of Second Best," Review of Economic Studies, No. 1, 1956, pp. 11-32.

${ }^{3}$ WHEREVER THE ELEMENTARY SCHOOL DISTRICT HAS ALREADY BECOME SUBSTANTIALLY INTEGRATED BY PUBLIC OR PRIVATE AGTION--SO THAT IT POSSESSES RACIAL PROPORTIONS CLOSE TO THOSE FOR THE CITY AS A WHOLE--OR WHEREVER FIRM PLANS OR CLEARLY SPECIFIED PROJECTS WILL PRODUCE SUCH A SITUATION IN THE NEAR FUTURE, THE NEIGHBORHOOD SCHOOL SYSTEM SHOULD NOT BE ALTERED AND ALL CHILDREN IN SUCH DISTRICTS SHOULD BE ASSIGNED TO THE NEAREST ELEMENTARY, JUNIOR HIGH, AND HIGH SCHOOLS TO THE EXTENT OF THE PHYSICAL CAPACITIES OF THE RESPECTIVE SCHOOLS.

4 Note the similarity of this approach to the pricing practices espoused by Oscar Lange and Fred M. Taylor, On the Economic Theory of Socialism (Minneapolis, Minn.: The University of Minnesota Press, 1938).

${ }^{5}$ Note that the policy "works" only within the confines of a given political jurisdiction. Where nearby political jurisdictions provide safe havens at low cost, the desired results may not be forthcoming. This, too, is a commonplace result because any cartel must encompass a large part of the market before it can effectuate its policies. Indeed, this is a touchstone for many urban and regional problems. 